\title{
AUTONOMY IN THE BEHAVIOR OF JUVENILES AND MINORS UNDER THE INFLUENCE OF THE POSTMODERN CRISIS
}

\author{
R. Vasilev* \\ Department of Social Activities, Faculty of Medicine, Trakia University., Stara Zagora, Bulgaria
}

\begin{abstract}
The aim of this research is to analyze the behavior of minors and juveniles in the contemporary social environment. In this sense, the term "autonomy" is recognized and regarded by the author as the personal social space of growing, education and attitude towards the realities of the social environment and the influence it exercises on young people.
\end{abstract}

Key words: Autonomy, moral, crisis, society, minors, juveniles.

\section{The problem investigated in this paper is as follows:}

The issue discussed is the role played by the crisis of the postmodern society, with an emphasis on the value of moral and legal norms governing the behavioral space of this category of youngsters.

\section{INTRODUCTION}

Under the influence of the crisis of values, including the existing moral, legal and ethical norms, the personal autonomy of minors and juveniles has changed its form. The time of the Enlightenment dominated by free will and individuality, as well as rejection of the accepted authorities, is long gone. Today it has been replaced by dependence imposed by ,... a world much different than the one we have begun to understand, and the moment our understanding adapts to the new reality, the world will probably become drastically different", as Brzezinski summarizes (1).

For minors and juveniles, their existence in a social space of constantly shifting moral and legal norms, a world of drastically changing social models, has put them in danger. There is a discrepancy between their beliefs and knowledge of its reality and of the moral, ethical and socio-legal principles

* Correspondence to: Rumen Vasilev Vasilev PhD student, lawyer Assistant Professor, Department of Social, Activities, Faculty of Medicine, Trakia University, 11 Armejska str., , 6000 Stara Zagora, Tel.: 042/644417, e-mail: rumvas2003@yahoo.com fundamentally accepted as true. The environment that has become their reality is hostile and uncontrollable.

The impact of the secularized social environment and thinking on children leads to depreciation of the role of the moral and ethical factors in their interactions and in particular to behavioral deviations. In this way, children lose certain aspects of their legal and moral clarity of purpose and autonomy, which is quite fickle to being with because of their young age. Exhibiting the innately human autonomy, formulating their goals and the means to attain them - all of these require willpower and character determination, because,.. the realm of goals is the realm of inner goal-directed willpower and every human being ought to consider himself a member of this realm. Or in other words, man must always be regarded as a goal. The human being is not an object, but the author and creator of his own deeds, and even the law of morality itself would never be fulfilled, if man did not desire to join the world of due through self-imposed duty. Man is a goal that exists in the realm of goals." (2). Their unfamiliarity with the ethical and religious values supports in them the model of destructive behavior and thinking, of aimlessness and acknowledged lack of perspective.

Today it is a difficult, even impossible task to direct youth toward the fundamental Christian postulates connected with humility, fear of God, love for our parents and our fellow men. 
„For three hundred years Western science pictured the world as a giant clock or machine, in which knowable causes produced predictable effects. It is a determinist, totally ordered universe, which, once set in motion, pre-programs all subsequent actions." (3). The world that Toffler speaks about is the predictable and recognizable world, one of knowledge and respect for human autonomy and its moral and legal characteristics. In contrast, today's postmodern world is one of increased anxiety and concern, lack of agreement concerning the universal values, ideas and ideals; lack of cultural and historical memory among the current generation of minors and juveniles. Society and the social system that the youth observe and develop in, which also affect their model of autonomy, are too inconstant. Moreover, even „...the conceptualization of society as a system becomes especially difficult because of the fact that the thought and the feeling of the observer are parts of the system themselves. Therefore, the observer views the system not_through its functioning, but from the perspective of his own wishes and the role he himself plays in it" writes Fromm. (5).

The postmodern models of social instability, whether defined as financial, economic or political, are in reality models of the crisis of values and morality. They are gates that are open or shut before the youth, and are tied to their moral and ethical conduct in society in accord with the existing legal norms. The minors' behavioral deviations are their reflection influenced by the state of the system. If the system is in a state of equilibrium, the children's psychosocial status and legal behavior will also be in equilibrium.

If that is not the case, it is not only the system that will be difficult to manage, but also those extremely important to society social segments connected with education, growth and preservation of autonomy, of the moral and social status of minors, i.e. it is entirely possible to disrupt and destroy the autonomous framework of moral and legal norms in which minors and juveniles grow up and develop.

When in their desires and hopes, the observers of the system do not see or identify in it the possibility to fulfill their aspirations and beliefs; they will seek a way of circumventing or overcoming it. In such cases, in search of realizing their innate autonomy, in search of their own self, their efforts are directed toward violating the legal space, its moral norms and boundaries. The uneducated, mentally vulnerable, demotivated and powerless personality of the child might easily change the characteristics of his model of behavior, which often enters into the realm of the deviation. The autonomous framework of its psychosocial portrayal is affected by the crisis of the social environment and it is often transgressed against, i.e. it often transcends its moral, ethical, social and legal boundaries. The order (or rather disorder in the shifting political and economic models) in the social environment, the family, the school and the state has its own regulatory mechanisms, imposes its own norms, but they are often neglected by the category of offenders discussed in this article because of their temporal instability.

This is not about orders that need to be followed by the minors and juveniles in their social environment, but about understanding and compliance with the existing socio-cultural models, which have their own moral, ethical and legal significance in society. The process of preserving and realizing the socio-cultural models shapes the autonomous character of minors and juveniles, but in order for them to preserve the framework of their identity, the state has to establish the model that cultivates in them the fundamental awareness of social activity, social discipline and a high level of self-control.

In his „Individualism and Economic Order” Hayek writes: „,...an individualist order must rest on the enforcement of abstracts principles rather than on the enforcement of specific orders", which means that all of us (minors and juveniles included) have no choice but to comply with the legal system that is in place and operation in our social space. (4). It is completely certain that Hayek is right when he concludes that norms and principles are a form of coercion for all. The problem is that the segments that constitute social space are much more detailed and we have more and more new laws, multiple statutes, ordinances and an increasing number of legal acts in general, while the number of minors whose behavior violates those acts is also on the rise. Or as Fromm states,$\ldots$ our entire system is in a state of serious loss of equilibrium and a certain part of it appears to have lost its regenerative powers and adaptability" (5). Trying to keep the "system" (i.e. the social environment) from the instability and its recessive characteristics in equilibrium, we (as a society) will also maintain the autonomous nature of the category of minors and juveniles. Furthermore, we will create those moral, ethical, social and legal models that would affect the parameters of child behavior that lead to deviation. 
On the one hand, we all need to be especially careful when applying our experience and knowledge, when communicating with those children, when analyzing their behavior as equals, when trying to help in their efforts to preserve their autonomy of identity. On the other hand (which would lead to preservation of this autonomous framework, their personal socio-cultural identity), the complex process of preserving, applying and fulfilling these models of behavior demands self-discipline and a high degree of self-control from the minors and juveniles. In situations of social crisis, it is important to figure out to what extent society is capable of overcoming the crisis and how long this could take. Because, as Fromm says, „... whether a system will regain its equilibrium or fall apart depends on its ability to make the corresponding inner changes. "(5). Thus, the time it takes a society to overcome a crisis is important for the stability of the social framework and moral and legal models it contains.

In any event, during this period more children and citizens will be born, will grow up, will be raised and educated in this society. The problem would be especially severe if they reach the age of majority during a time of crisis. The model of their autonomous nature will be destroyed and they will lose their autonomy of identity and moral values. This drastic outcome is possible, but at all costs it should not be allowed to materialize.

The duration of the crisis in the postmodern society, or the restoration of the equilibrium, is especially important when it comes to the children growing up and developing at the time, who are faced with the formidable task of protecting and preserving themselves, their essence and moral values.

\section{CONCLUSION}

We all need to lend our support to the social system, so that the democratic paths and models contributing to the restoration of balance and the legal order in it materialize quickly and in the least painful and least traumatizing manner (in the moral, sociocultural and psycho-social aspect), because crisis situations always bring about legal disorder. All elements of the social space are valuable and important for the direction of development of a child's personality in a society in crisis, not just time. In order to halt the moral decay, restore the power of law, reestablish the moral and ethical norms and the spiritual values in the social domain (viewed as an influence on the autonomous nature of juveniles), it is essential to have the political will of those in power.

All models of behavior are possible, important and equally valuable, both personal and institutional ones. However, it should not be forgotten that their fulfillment would be successful only when there is a common direction, common goals, clear and legally identifiable common temporal horizons and equally important will of all subjects in society.

It is not just the political will that is needed the moral and social support in the community is also required to bring back society to its fundamental pursuit of moral and legal norms to uphold.

The personal factors and interests stemming from human relations need to be directed toward harmonization of the social environment and the possibility for minors and juveniles to develop in the social milieu as equals.

The materialization, or rather restoration of these models, would bring back the balance to the social system, would strengthen the autonomous nature of a child's personality, as well as the domain of its moral, social and legal characteristics.

\section{REFERENCES}

1. Zbigniew Brzezinski, Out of Control: Global Turmoil on the Eve of the 21st Century, S., 1994, pp. 7-8.

2. Krasimira Benkova, Georgi Kolev, Passages and Commentary on Ethics (Tekstove $i$ komentari po etika), Stara Zagora, ,Alfamarket +”, 2011, p. 15

3. Alvin Toffler, Powershift, S., 1996, p. 519.

4. Friedrich Hayek, Individualism and Economic Order, p. 28.

5. Erich Fromm, On Being Human, S., 2004, pp. $64,69 \& 75$. 